\title{
AKTIVITAS ANTIKANKER SENYAWA ASILFLOROGLUSINOL DARI BIJI Melicope incana TERHADAP SEL KANKER PAYUDARA MCF-7
}

\author{
Tiara Nurul Hikmah, Muhammad Fajar Aldin, Ratih Dewi Saputri, Tjitjik Srie \\ Tjahjandarie, Mulyadi Tanjung*
}

Kimia Organik Bahan Alam, Departemen Kimia, Fakultas Sains dan Teknologi, Universitas Airlangga Surabaya, Jawa Timur, Indonesia

\section{Info Article}

Submitted :

5 Juni 2020

\section{Revised :}

12 November 2020

Accepted :

14 November 2020

\section{Corresponding Author :}

Mulyadi Tanjung

\section{Email :}

mulyadi-t@fst.unair.ac.id

\section{ABSTRAK}

Melicope incana merupakan salah satu spesies tumbuhan dari famili Rutaceae. Melicope menghasilkan senyawa fenolik, antaralain alkaloid, asilfloroglusinol, flavonoid, dan kuumarin. Penelitian ini bertujuan untuk mengisolasi senyawa turunan asilfloroglusinol yang terdapat pada biji $M$. incana. Ekstraksi senyawa asilfloroglusinol dengan metanol menggunakan metode maserasipada suhu kamar. Pemisahan dan pemurnian menggunakan kombinasi kromatografi kolom dan kromatografi radial. Dua senyawa asilfloroglusinol telah berhasil diisolasi yaitu $3^{\prime}$-geranil-2', 4',6'-trihidroksi-asetofenon (1) dan 3'-isoprenil2',4',6'-trihidroksiasetofenon (2). Struktur kedua senyawa ditetapkan berdasarkan analisis spektroskopi UV, IR, 1D dan 2D NMR. Uji aktivitas antikanker senyawa 1 dan $\mathbf{2}$ terhadap sel kanker payudara MCF-7 memperlihatkan nilai $I_{50}$ sebesar 48,98 dan 4,30 $\mu \mathrm{g} / \mathrm{mL}$.

Kata kunci: Melicope incana, asilfloroglusinol, antikanker, sel MCF-7

\section{Access this article}

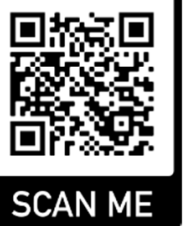

\section{ABSTRACT}

Melicope incana is one of the plant species that belongs to family Rutaceae. Melicope produces phenolic compounds, including alkaloids, acylphloroglucinol, flavonoids, and coumarins. This study aims to isolate the acylphloroglucinoderivatives found in $M$. incana seeds. Extraction of acylphloroglucinol derivatives with methanol using the maceration method at room temperature. Separation and purification using a combination of column chromatography, and radial chromatography. Two acylphloroglucinol compounds have been isolated, namely 3'-geranyl-2', 4',6'trihydroxyacetophenone (1) and 3'-isoprenyl-2',4',6'-trihydroxy acetophenone (2). The structure of the two compounds was determined based on UV, IR, 1D, and 2D NMR spectroscopic analysis. Anticancer activity of compounds $\mathbf{1}$ and $\mathbf{2}$ against breast 
cancer cells MCF-7 showed IC 50 values of 48.98 and $4.30 \mu \mathrm{g} / \mathrm{mL}$, respectively.

Keywords: Melicope incana, acylphloroglucinol, anticancer, MCF-7 cells

\section{PENDAHULUAN}

Melicope merupakan salah satu genus terbesar famili Rutaceae yang tumbuh di daerah tropis. Melicope menghasilkan senyawa metabolit sekunder seperti golongan alkaloid, kuinolin, asilfloroglusinol, flavonoid, dan fenilpropanoid, aril propanoid, kumarin dan lignan (Chen, 2003; Chou, 2005; Nakashima, 2012; Saputri, 2018). Senyawa asilfloroglusinol Melicope merupakan senyawa golongan poliketida dan memperlihatkan aktivitas terhadap berbagai sel kanker (Chou, 2005; Saputri, 2018; Xu, 2016). Biosintesis senyawa asilfloroglusinol berasal dari penggabungan empat asetil koenzim $A$ melalui reaksi kondensasi menghasilkan senyawa tetraketida. Reaksi siklisasi yang diaktifkan oleh $\mathrm{Ha}$ antar unit asetil koenzim A dan dikuti oleh reaksi tautomeri (keto-enol) menghasilkan senyawa asilfloroglusinol. Senyawa asilfloroglusinol mengalami reaksi substitusi elektrofilik pengarah ortho atau para dari substituent hidroksi dengan rantai samping terpenil menghasilkan turunan asilfloroglusinol yang beragam (Nakashima, 2012). Rantai samping terpenil pada Melicope umumnya berupa isoprenil $\left(C_{5}\right)$, geranil $\left(C_{10}\right)$, dan farnesil $\left(C_{15}\right)$ yang terikat pada inti aromatik. Adanya rantai samping terpenil yang terlihat pada inti fenolik merupakan ciri senyawa Melicope (Nguyen, 2016; Saputri, 2019; Xu, 2016).

Melicope incana merupakan salah satu tumbuhan endemik Sumatera. Data fitokimia $M$. incana sampai saat ini belum ada laporan ilmiahnya. Penelitian ini bertujuan untuk mengisolasi senyawa asilfloroglusinol yang terdapat dalam biji Melicope incana. Uji aktivitas antikankersenyawa asilfloroglusinol hasil isolasi dilakukan terhadap sel kanker payudara MCF-7 menggunakan metode MTT juga akan dibahas dalam artikel ini.

\section{METODE PENELITIAN}

\subsection{Prosedur Umum}

Pelarut yang digunakan untuk ekstraksi, pemisahan, dan pemurnian senyawa diantaranya adalah metanol, $n$ heksana, kloroform, diisopropileter, aseton, dan etil asetat. Pelat KLT Kieselgel $60 \mathrm{GF}_{254} 0.25 \mathrm{~mm}$ (Merck) untuk analisis kromatografi lapis tipis (KLT), silika gel 60 untuk kromatografi kolom dan silika gel 60 $\mathrm{PF}_{254}$ untuk kromatografi radial. Spektrum UV ditetapkan dengan spektrofotometer UV-Vis Shimadzu 1800 dan spektrum IR diukur dengan spektrofotometer IR Perkin Elmer 100.Analisis spektrum NMR menggunakan NMR JEOL ECA 400 yang beroperasi pada $400 \mathrm{MHz}$ ('H-NMR) dan $100 \mathrm{MHz}\left({ }^{13} \mathrm{C}-\mathrm{NMR}\right)$. Sel kanker payudara T47D dikulturkan pada media RPMI-1640 dalam $1 \mathrm{~mL}$ fetal bovine serum (FBS), streptomisin $100 \mu \mathrm{g} / \mathrm{mL}$, penisilin 100 $\mu \mathrm{g} / \mathrm{mL}$, dan natrium bikarbonat dalam inkubator $\mathrm{CO}_{2}$ selama 24 jam pada suhu $37^{\circ} \mathrm{C}$ (Tanjung, 2019). Uji aktivitas antikanker senyawa asilfloroglusinol terhadap sel kanker payudara MCF-7 menggunakan metode MTT [3-(4,5- 
dimethylthiazole-2-yl)-2,5-

diphenyltetrazolium bromide]. Chem Bio Draw Ultra 12.0 merupakan software untuk menggambarkan struktur senyawa.

\subsection{Bahan Tanaman}

Sampel yang diteliti dalam penelitian ini adalah biji $M$. incana yang berasal dari Kecamatan Lipat Kain, Kabupaten Kampar, Riau. Identifikasi tumbuhan dilakukan di Herbarium Bogorensis, LIPI Biologi, Cibinong, Bogor, Jawa Barat.

\subsection{Ekstraksi dan Isolasi}

Ekstraksi senyawa asilfloroglusinol yang terdapat dalam serbuk kering biji $M$. incana sebanyak 0,6 kg dengan metanol sebanyak 3 L menggunakan metode maserasi pada suhu kamar selama tiga hari dengan pengulangan dua kali. Pelarut diuapkan menggunakan rotary vacuum evaporator sehingga menghasilkan ekstrak kental metanol. Senyawa nonpolar (terpenoid dan asam lemak) yang terdapat dalam ekstrak metanol dipartisi dengan $n$ - heksana. Ekstrak metanol ditambahkan air sebanyak $10 \% \mathrm{v} / \mathrm{v}$ kemudian dipartisi dengan etil asetat menghasilkan ekstrak kental etil asetat sebanyak 25,0 gr. Fraksinasi ekstrak etil asetat $(25,0 \mathrm{gr})$ dengan kromatografi kolom gravitasi dengan eluen $n$-heksana:etil asetat (9:1 sampai 1:1) menghasilkan tiga fraksi utama yakni fraksi A-C. Pemisahan fraksi A (12 g) dengan sephadex LH-20 menggunakan metanol sebagai eluen menghasilkan subfraksi $A_{1}$ dan $A_{2}$. Pemisahan subfraksi $A_{1}$ menggunakan kromatografi radial dengan campuran $\mathrm{n}$ heksana: $\mathrm{CHCl}_{3}=(1: 1$ dan 3:7) (v/v) dan $\mathrm{CHCl}_{3}$ :etil asetat $=(9: 1)(\mathrm{v} / \mathrm{v})$ menghasilkan dua subfraksi yaitu $A_{11}$ dan $A_{12}$. Pemurnian subfraksi $A_{11}$ dan $A_{12}$ menggunakan kromatografi radial. Subfraksi $A_{11}$ menggunakan eluen $n$-heksana:aseton $=$ (9:1; 17:3 dan 4:1) menghasilkan senyawa 1 sebanyak $25 \mathrm{mg}$ dan subfraksi $\mathrm{A}_{12}$ menggunakan eluen $n$-heksana-aseton (4:1 dan 3:1) menghasilkan senyawa 2 sebanyak 39 mg (Gambar 1).

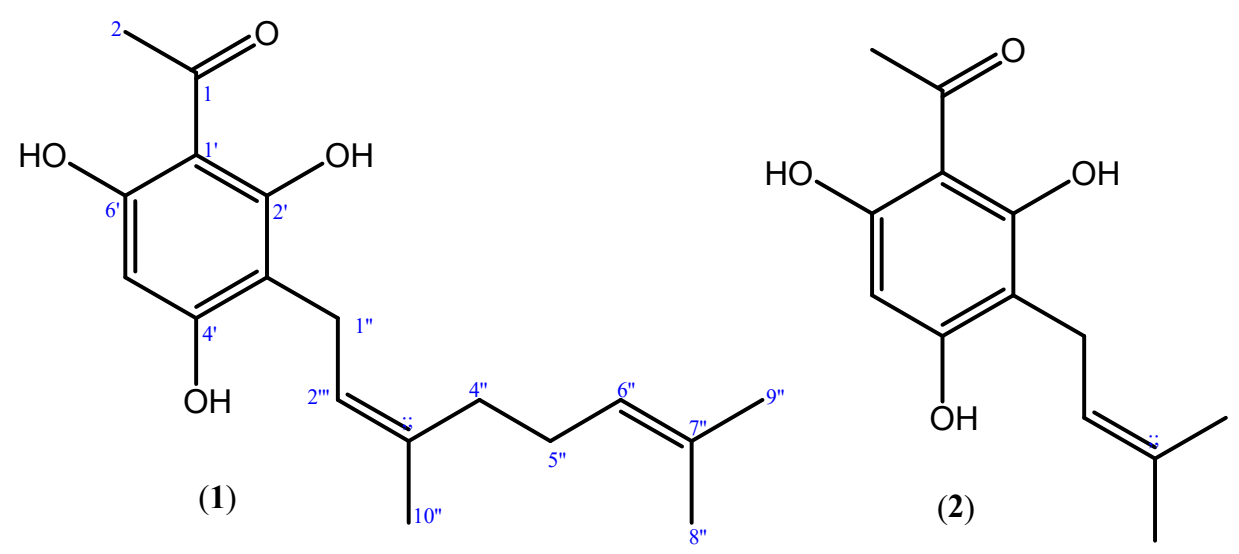

Gambar 1. Senyawa asilfloroglusinol M. incana

\subsection{Uji Antikanker}

Uji aktivitas antikanker senyawa asilfloroglusinol hasil isolasi terhadap sel kanker payudara MCF-7 dilakukan menggunakan metode MTT [3-(4,5dimethylthiazole-2-yl)-2,5-

diphenyltetrazolium bromide] secara in vitro yang umum digunakan untuk 
penentuan toksisitas suatu senyawa terhadap sel kanker. Sel kanker payudara MCF-7 yang sebelumnya telah diinkubasi ditambahkan dengan senyawa uji dalam berbagai konsentrasi $(6,25 ; 12,5 ; 25 ; 50$; 100 ppm). Sel MCF-7 yang telah dikultur diberi larutan uji dengan berbagai konsentrasi (dibuat replikasi sebanyak tiga kali untuk masing-masing konsentrasi) dan kemudian diinkubasi selama 24 jam. Aktivitas pertumbuhan sel dapat diamati setelah penambahan garam MTT. Garam MTT ditambahkan setelah 24 jam penambahan larutan uji. Setelah ditambahan garam MTT, diinkubasi kembali selama 4 jam pada suhu $37^{\circ} \mathrm{C}$. Aktivitas pertumbuhan sel setelah perlakuan diukur dengan pemberian larutan MTT dengan mengamati perubahan warna yang terjadi pada kristal formazan. Perubahan warna pada garam MTT berbanding lurus dengan aktivitas penghambatan pertumbuhan sel kanker. Kristal yang terbentuk kemudian dilarutkan dengan dimetil sulfoksida (DMSO) lalu dianalisis menggunakan micro plate reader pada panjang gelombang 570 nm (Aldin, 2019; Tjahjandarie, 2019).

\section{HASIL DAN PEMBAHASAN}

Senyawa

trihidroksi-asetofenon padatan berwarna kuning muda dengan titik leleh $140-142^{\circ}$ C. Spektrum UV senyawa 1 dalam metanol menunjukkan serapan maksimum pada $\lambda_{\text {maks }} \mathrm{nm}$ ( $\log \varepsilon$ ): $222(4,27)$ dan 291 (4,33) yang merupakan ciri senyawa turunan asifloroglusinol (Tanjung, 2018). Spektrum IR senyawa 1 dalam pelet $\mathrm{KBr}$ memperlihatkan pita serapan pada bilangan gelombang $v(\mathrm{~cm})$ ${ }^{1}$ : 3406 (vibrasi ulur OH); 1639 (vibrasi ulur
$\mathrm{C}=\mathrm{O}$ terkonjugasi); 1597-1450 (vibrasi ulur $\mathrm{C}=\mathrm{C}$ aromatik). Spektrum ${ }^{1} \mathrm{H}-\mathrm{NMR}$ dalam $\mathrm{CDCl}_{3}$ memperlihatkan satu sinyal proton deshielding metil dari asetil pada $\delta_{H} 2,59$ $(3 \mathrm{H}, \mathrm{s}, \mathrm{H}-2)$ dan satu sinyal singlet aromatik terisolasi pada $\delta_{\mathrm{H}} 6,05\left(1 \mathrm{H}, \quad s, \mathrm{H}-5^{\prime}\right)$. Spektrum ${ }^{1} \mathrm{H}-\mathrm{NMR}$ senyawa $\mathbf{1}$ juga memperlihatkan tiga sinyal proton hidroksi $\left[\delta_{H} 13,93\left(1 \mathrm{H}, s^{\prime} 2^{\prime}-\mathrm{OH}\right) ; \delta_{H} 9,44(1 \mathrm{H}\right.$, $\left.s, 6^{\prime}-\mathrm{OH}\right) ; \delta_{H} 9,03\left(\left(1 \mathrm{H}, s, 4^{\prime}-\mathrm{OH}\right)\right]$ yang merupakan ciri senyawa turunan asifloroglusinol (Tanjung, 2018). Spektrum ${ }^{1} \mathrm{H}-\mathrm{NMR}$ senyawa $\mathbf{1}$ juga memperlihatkan adanya rantai samping geranil yang terdiri dari dua sinyal proton vinilik $\left[\delta_{H} 5,23(1 \mathrm{H}\right.$, $\left.t m, J=7,2 \mathrm{~Hz}, \mathrm{H}-2^{\prime \prime}\right), \delta_{\mathrm{H}} 5,06(1 \mathrm{H}, t m, J=7,2$ $\left.\left.\mathrm{Hz}, \mathrm{H}-6^{\prime \prime}\right)\right]$, tiga sinyal proton metilen $\left[\delta_{\mathrm{H}}\right.$ $3,24\left(2 \mathrm{H}, d, J=7,0 \mathrm{~Hz}, \mathrm{H}-1^{\prime \prime}\right), \delta_{\mathrm{H}} 2,03(2 \mathrm{H}, m$, $\left.\left.\mathrm{H}-5^{\prime \prime}\right), \delta_{\mathrm{H}} 1,92\left(2 \mathrm{H}, m, \mathrm{H}-6^{\prime \prime}\right),\right]$, serta tiga sinyal proton metil $\left[\delta_{H} 1.74\left(3 \mathrm{H}, \mathrm{s}, \mathrm{H}-10^{\prime \prime}\right)\right.$, $\left.\delta_{H} 1.60\left(3 \mathrm{H}, \mathrm{s}, \mathrm{H}-8^{\prime \prime}\right), \delta_{\mathrm{H}} 1.54\left(3 \mathrm{H}, \mathrm{s}, \mathrm{H}-9^{\prime \prime}\right)\right]$. Spektrum ${ }^{13} \mathrm{C}-\mathrm{NMR}$ senyawa 1 memperlihatkan 18 sinyal karbon yang terpisah secara sempurna. Tiga sinyal karbon oksiaril $\left[\delta_{c} 164,9 ; \delta_{c} 162,7\right.$ dan $\delta_{c}$ $160,6]$ dan sinyal karbon asetil $\left[\delta_{c} 203,7\right.$; $\left.\delta_{c} 32,8\right]$ merupakan ciri karbon asilfloroglusinol (Shaari, 2006). Penempatan rantai samping geranil ditetapkan berdasarkan analisis spektrum HMBC. Sinyal proton metil dari asetil pada $\delta_{H} \quad 2,59(\mathrm{H}-2)$ memperlihatkan korelasi dengan karbon C-1 ( $\left.\delta_{c} 203,7\right)$. Sinyal proton hidroksi pada $\delta_{H} 13,93\left(2^{\prime}-\mathrm{OH}\right)$ memperlihatkan korelasi dengan $\mathrm{C}-1^{\prime}\left(\delta_{\mathrm{C}}\right.$ $105,3)$ dan $C-2^{\prime}\left(\delta_{c} 164,9\right)$. Sinyal proton hidroksi yang lain pada $\delta_{H} 9,44\left(6^{\prime}-\mathrm{OH}\right)$ memperlihatkan korelasi dengan $\mathrm{C}-1^{\prime}$ dan C-6' $\left(\delta_{c}\right.$ 160,6). Sinyal proton aromatik pada $\delta_{\mathrm{H}} 6,05\left(\mathrm{H}-5^{\prime}\right)$ berkorelasi dengan $\mathrm{C}-1^{\prime}$ dan $C-4^{\prime}\left(\delta_{C} 162,7\right)$. Sinyal proton metilen dari geranil pada $\delta_{H} 3,24\left(H-1^{\prime \prime}\right)$ berkorelasi 
dengan C-4', C-3' $\left(\delta_{c} 107,7\right), C-2^{\prime \prime}\left(\delta_{c} 124,0\right)$ dan C-3" $\left(\delta_{c} 134,5\right)$. Hasil korelasi sinyal metilen dengan sinyal karbonnya menunjukkan geranil terikat di C-3". Berdasarkan analisis 1D dan 2D NMR (Tabel 1) maka sstruktur senyawa $\mathbf{1}$ isolasi adalah trihidroksiasetofenon (Shaari, 2006). Korelasi antara sinyal proton dengan karbon dalam dua atau tiga ikatan yang mendukung struktur senyawa 3 '-geranil$2^{\prime}, 4^{\prime}, 6^{\prime}$-trihidroksiasetofenon pada spektrum HMBC dapat dilihat pada Tabel 1 dan Gambar 2.

Tabel 1. Data spektrum NMR 3'-geranil-2', $4^{\prime}, 6^{\prime}$-trihidroksiasetofenon dalam CDCl3

\begin{tabular}{|c|c|c|c|}
\hline No. C & $\delta_{H}($ mult, dalam Hz) & $\delta_{c}$ & HMBC \\
\hline 1 & - & 203,7 & - \\
\hline 2 & $2,59(s)$ & 32,8 & $C-1$ \\
\hline $1^{\prime}$ & - & 105,3 & - \\
\hline $2^{\prime}$ & - & 164.9 & - \\
\hline $3^{\prime}$ & - & 107,7 & - \\
\hline $4^{\prime}$ & - & 162,7 & - \\
\hline $5^{\prime}$ & $6,05(s)$ & 94,8 & $C-1^{\prime}, C-4^{\prime}$ \\
\hline $6^{\prime}$ & - & 160,6 & - \\
\hline $1^{\prime \prime}$ & $3,24(d, 7,0)$ & 21,8 & $C-3^{\prime}, C-4^{\prime}, C-2^{\prime \prime}, C-3^{\prime \prime}$ \\
\hline $2^{\prime \prime}$ & $5,23(t, 7,2)$ & 124,0 & C-4", C-10" \\
\hline $3 "$ & - & 134,5 & - \\
\hline $4 "$ & $1,92(m)$ & 40,5 & C-2". C-3", C-4", C-5" \\
\hline $5^{\prime \prime}$ & $2,03(m)$ & 27,4 & C-8", C-9" \\
\hline $6 "$ & $5,06(t, 7,2)$ & 125,2 & $C-8^{\prime \prime}, C-9^{\prime \prime}$ \\
\hline $7^{\prime \prime}$ & - & 131,5 & - \\
\hline $8 "$ & $1,60(s)$ & 25,8 & C-6", C-7", C-9" \\
\hline $9^{\prime \prime}$ & $1,54(s)$ & 17,6 & C-6", C-7", C-8" \\
\hline $10^{\prime \prime}$ & $1,74(s)$ & 16,2 & C-2", C-3", C-4" \\
\hline $2^{\prime}-\mathrm{OH}$ & $13.93(s)$ & - & $C-1^{\prime}, C-2^{\prime}$ \\
\hline $4^{\prime}-\mathrm{OH}$ & $9,03(s)$ & - & $C-3^{\prime} ; C-4^{\prime}$ \\
\hline $6^{\prime}-\mathrm{OH}$ & $9,44(s)$ & - & $C-1^{\prime} ; C-6^{\prime}$ \\
\hline
\end{tabular}

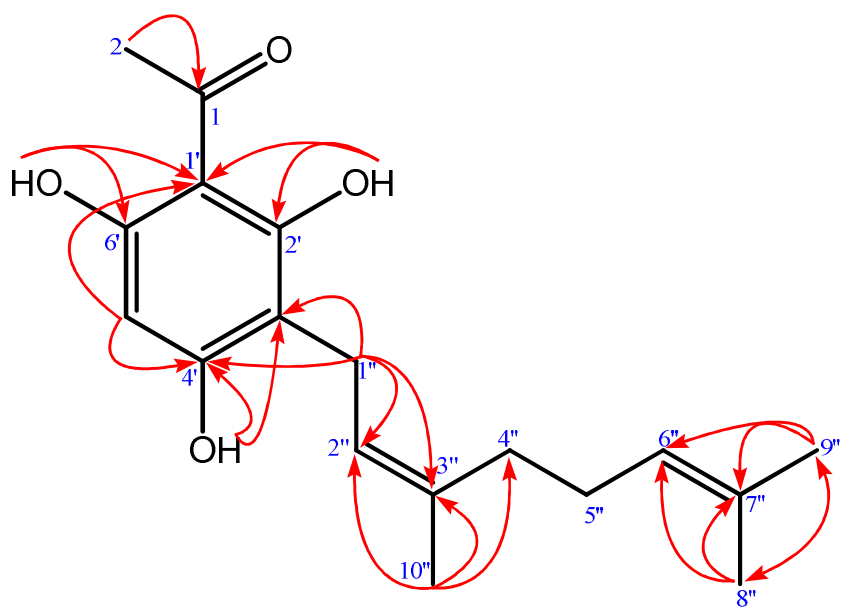

Gambar 2. Spektrum HMBC yang penting pada senyawa 1

Senyawa $\quad 3^{\prime}$-isoprenil-2', $4^{\prime}, 6^{\prime}$ -

trihidroksi-asetofenon (2) berwujud padatan kuning muda dengan titik leleh $191-192^{\circ}$ C. Spektrum UV $\left(\lambda_{\text {maks }} n\right.$ m (log $\left.\varepsilon\right)$ :
226,5 (4,04) dan 290,5 (4,14) danspektrum IR $\left(\mathrm{v}\left(\mathrm{cm}^{-1}\right): 3456,1641\right.$ dan 1572-1450) mirip dengan senyawa 1 . Spektrum ${ }^{1} \mathrm{H}$ NMR dalam $\mathrm{CDCl}_{3}$ senyawa 2juga 
memperlihatkan kemiripan dengan $\mathbf{1}$, yakni sinyal proton metil dari asetil, $\delta_{H} 2,59$ $(\mathrm{H}-2)$, sinyal singlet aromatik $, \delta_{\mathrm{H}} 6,05\left(\mathrm{H}-5^{\prime}\right)$ dan tiga sinyal proton hidroksi $\left[\delta_{H} 13,96\left(2^{\prime}-\right.\right.$ $\left.\mathrm{OH}), \delta_{\mathrm{H}} 9,51 \quad\left(6^{\prime}-\mathrm{OH}\right), \delta_{\mathrm{H}} 9,13\left(4^{\prime}-\mathrm{OH}\right)\right]$. Perbedaan utama senyawa 2 memperlihatkan adanya rantai samping isoprenil yang terikat pada C-3'. Sinyal proton isoprenil senyawa $\mathbf{2}$ terdiri dari satu sinyal proton vinilik pada $\delta_{H} 5,20(1 \mathrm{H}, t m, J$ $\left.=7,3 \mathrm{~Hz}, \mathrm{H}-2^{\prime \prime}\right)$, satu sinyal proton metilen pada $\delta_{\mathrm{H}} 3,21\left(2 \mathrm{H}, d, J=7,2 \mathrm{~Hz}, \mathrm{H}-1^{\prime \prime}\right)$, dan dua sinyal metil $\left[\delta_{H} 1,72\left(3 \mathrm{H}, \mathrm{s}, \mathrm{H}-4^{\prime \prime}\right), \delta_{H}\right.$ $\left.1,60\left(3 \mathrm{H}, \mathrm{s}, \mathrm{H}-4^{\prime \prime}\right)\right]$. Analisis spektrum ${ }^{13} \mathrm{C}-$ NMR senyawa 2 memperlihatkan 13 sinyal atom karbon yang terpisah secara sempurna. Berdasarkan analisis spektrum HMQC dan HMBC maka struktur senyawa 2 adalah 3'-isoprenil-2', 4',6'trihidroksiasetofenon (Tanjung, 2018). Korelasi HMBC antara sinyal proton dan karbon dalam dua atau tiga ikatan yang mendukung struktur senyawa 3 '-isoprenil$2^{\prime}, 4^{\prime}, 6^{\prime}$-trihidroksiasetofenon hasil isolasi dapat dilihat pada Tabel 2 dan Gambar 3.

Tabel 2. Data spektrum NMR 3'-isoprenil-2', $4^{\prime}, 6^{\prime}$-trihidroksiasetofenon dalam $\mathrm{CDCl}_{3}$

\begin{tabular}{|c|c|c|c|}
\hline No. C & $\delta_{H}($ mult, dalam Hz) & $\delta_{c}$ & HMBC \\
\hline 1 & - & 203.7 & - \\
\hline 2 & $2.59(s)$ & 32.8 & $C-1$ \\
\hline $1^{\prime}$ & - & 105.2 & - \\
\hline $2^{\prime}$ & - & 164.8 & - \\
\hline $3^{\prime}$ & - & 107.6 & - \\
\hline $4^{\prime}$ & - & 160.7 & - \\
\hline $5^{\prime}$ & $6.05(s)$ & 94.8 & $C-1^{\prime}, C-4^{\prime}$ \\
\hline $6^{\prime}$ & - & 162.7 & - \\
\hline $1^{\prime \prime}$ & $3.21(d, 7.2)$ & 21.8 & $C-3^{\prime}, C-4^{\prime}, C-2^{\prime \prime}, C-3^{\prime \prime}$ \\
\hline $2 "$ & $5.20(t m, 7.3)$ & 124.1 & C-4", C-10" \\
\hline $3 "$ & - & 130.7 & - \\
\hline $4 "$ & $1.72(s)$ & 17.8 & C-2". C-3", C-4", C-5" \\
\hline $5 "$ & $1.60(s)$ & 25.8 & C-8", C-9" \\
\hline $2^{\prime}-\mathrm{OH}$ & $13.96(s)$ & - & $C-1^{\prime}, C-2^{\prime}$ \\
\hline $4^{\prime}-\mathrm{OH}$ & $9.13(s)$ & - & $C-3^{\prime} ; C-4^{\prime}$ \\
\hline $6^{\prime}-\mathrm{OH}$ & $9.51(s)$ & - & $C-1^{\prime} ; C-6^{\prime}$ \\
\hline
\end{tabular}

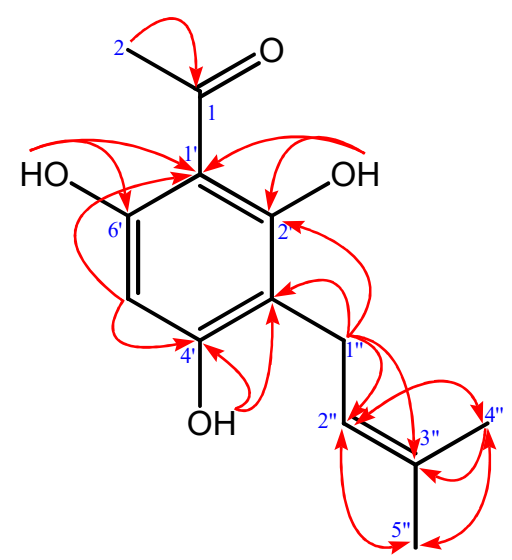

Gambar 3. Spektrum HMBC Spektrum HMBC yang penting pada senyawa 2

Uji aktivitas senyawa 3 '-geranil2',4',6'-trihidroksi-asetofenon (1) dan 3'isoprenil-2',4',6'-trihidroksiasetofenon (2) terhadap sel kanker payudara MCF-7 berdasarkan metode MTT. Pengamatan sel yang mati menggunakan mikroskop 
memperlihatkan warna garam MTT (kuning), sedangkan sel yang hidup akan bereaksi dengan garam MTT dan menampakkan warna kristal formazan (ungu). Senyawa 3'-geranil-2',4',6'trihidroksi-asetofenon (1) memperlihatkan aktivitas antikanker yakni nilai $\mathrm{IC}_{50}$ adalah $49,98 \pm 0,01 \mu \mathrm{g} / \mathrm{mL}$ dan dikategorikan tidak aktif. Senyawa 3'-isoprenil-2',4',6'trihidroksiasetofenon (2) memperlihatkan nilai $I_{50}$ sebesar $4,30 \pm 0,01 \mu \mathrm{g} / \mathrm{mL}$ dan dikategorikan lemah (Tjahjandarie, 2019). Adanya isoprenil yang terikat di C-3' pada senyawa 1 meningkatkan aktivitas antikanker disbanding geranil yang yang terikat di C-3' pada senyawa 2. Adanya rantai samping isoprenil dibanding dengan senyawa asifloroglusinol sederhana juga meningkatkan aktivitas antikanker (Saputri, 2018).

\section{KESIMPULAN}

Dua senyawa turunan

asilfloroglusinol, yaitu $3^{\prime}$-geranil-2', 4', 6'trihidroksiasetofenon (1) dan $3^{\prime}$-isoprenil2',4',6'-trihidroksiasetofenon (2) telah berhasil diisolasi dari biji $M$. incana. Struktur dari kedua senyawa ditetapkan berdasarkan analisis 1D NMR dan 2D NMR. Uji aktivitas antikanker terhadap sel kanker payudara MCF-7, senyawa 3'-geranil2', 4',6'-trihidroksiasetofenon

menunjukkan nilai $\mathrm{IC}_{50} 49,98 \mu \mathrm{g} / \mathrm{mL}$ dan dikategorikan tidak aktif dan 3'-isoprenil2',4',6'-trihidroksiasetofenon

memperlihatkan nilai nilai $\mathrm{IC}_{50} 4,30 \mu \mathrm{g} / \mathrm{mL}$ dan dikategorikan lemah.

\section{UCAPAN TERIMA KASIH}

Ucapan terimakasih disampaikan kepada Mr. Ismail Rachman, staf LIPI Biologi, Bogor atas pemberian sampel tumbuhan.

\section{DAFTAR PUSTAKA}

Aldin M.F., Saputri R.D., Tjahjandarie T.S., Tanjung M., 2019, Aktivitas antikanker senyawa stilbenoid dari daun Macaranga aleuritoides, Pharm. Med.J, 2, 1-7.

Chen J-J., Cho J-Y., Hwang T.L., Chen I-S., 2003, Benzoic acid derivatives, acetophenones, and antiinflammatory constituents from Melicope semecarpifolia, J. Nat. Prod., 71, 71-75.

Chou H-C., Chen J-J., Duh C-Y., Huang T-F., Chen I-S., 2005, Cytotoxic and antiplatelet aggregation constituents from the root wood of Melicope semecarpifolia, Planta Medica, 71, 10781081.

Nakashima K., Oyama M., Ito T., Witono J.R., Darnaedi D., Tanaka T., Murata J., linuma M., 2012. Melicodenines A and B, novel Diels-Alder type adducts isolated from Melicope denhamii, Tetrahedron, 52 (36), 4694-4696.

Nguyen N.H., Ha T.K., Choi S., Eum S., Lee C.H., Bach T.T., Chinh V.T., Oh W.K., 2016, Chemical constituents from Melicope pteleifolia leaves, Phytochemistry, 130, 291-300.

Saputri R.D., Tjahjandarie T.S., Tanjung M., 2019. Alkaloid furokuinolin dan asam sinamat ter-O-geranilasi dari kulit batang Melicope hookeri T.G. Hartley.J.Sains Kesehatan. 2 (1),1-7.

Saputri R.D., Tjahjandarie T.S., Tanjung M., 2018. Meliglabrin, a new flavonol derivative from the leaves of Melicope glabra (Blume) T.G. Hartley, Nat. Prod. Sci. 24,155-158.

Saputri R.D., Tanjung M., Tjahjandarie T.S., 2018. Cytotoxic activity of quilinone alkaloids and acylphloroglucinol from the leaves of Melicope denhamii.J. of Physics: Conf. Series 1095 (2018) 012031.

ShaariK., Safri, S., Abas, F., Lajis, N.N.H., IsrafD.A, 2006, A geranylacetophenone from the leaves of Melicope pteleifolia, Nat. Prod. Res., 20 (5), 415-419.

Tanjung M, Tjahjandarie TS, Saputri RD, Kurnia BD, Rachman MF, Syah YM. 2019. Calotetrapterins A-C, three new 
pyranoxanthones and their cytotoxicity from the stem bark of Calophyllum tetrapterum Miq. Nat Prod Res. 1-6.

Tanjung M., Nurmalasari I., Wilujeng Aisyah. K., Saputri, R.D., Rachmadiarti, F., Tjahjandarie, T. S., 2018, Acronyculatin $P$, A New Isoprenylated Acetophenonefrom the Stem Bark of Acronychia pedunculata, Nat. Prod. Sci., 4, 284-287.
Tjahjandarie T.S., Tanjung M., Saputri R.D., Nadar P.B., Aldin M.F., Marliana E., Permadi A. 2019. Flavestin K, An isoprenylated stilbene from the leaves of Macaranga recurvata Gage, Nat. Prod. Sci. 25(3), 244-247.

Xu, J., Sun, X., Liu, X., Peng, M., Li, S., Jin, D.-Q., Lee, D., Bartlam, M., Guo, Y., 2016, Phytochemical Constituents from Melicope pteleifolia that Promote Neurite Outgrowth in PC12 Cells, J Funct. Foods, 23, 565-572. 